\title{
COMPARISON OF TWO-PHASE PRESSURE DROP MODELS FOR CONDENSING FLOWS IN HORIZONTAL TUBES
}

ALINA FILIP - Lecturer, Dr. Eng., Technical University of Civil Engineering Bucharest, Thermal Engineering Department, e-mail: alinafilip69@yahoo.com

FLORIN BĂLTĂREŢU - Associate Professor, Dr. Eng., Technical University of Civil Engineering Bucharest, Thermal Engineering Department, e-mail: flbaltaretu@yahoo.com

RADU-MIRCEA DAMIAN, - Professor, Dr. Eng., Technical University of Civil Engineering Bucharest, Department of Hydraulics and Environmental Protection, e-mail: damian@astralnet.ro, rdamian@hidraulica.utcb.ro

\begin{abstract}
An important parameter in the hydraulic design of refrigeration and air-conditioning systems is the two-phase flow pressure drop. In this paper, the authors compare the numerical results obtained by using seven two-phase pressure-drop models with the experimental results found in the scientific literature, for the condensation of R600a and R717 (Ammonia $=$ NH3) in horizontal tubes. Different mass flow rates and different conditions have been considered in order to see which correlation is applicable under specific operation conditions.
\end{abstract}

Keywords: two-phase pressure drop, refrigerant, condensation

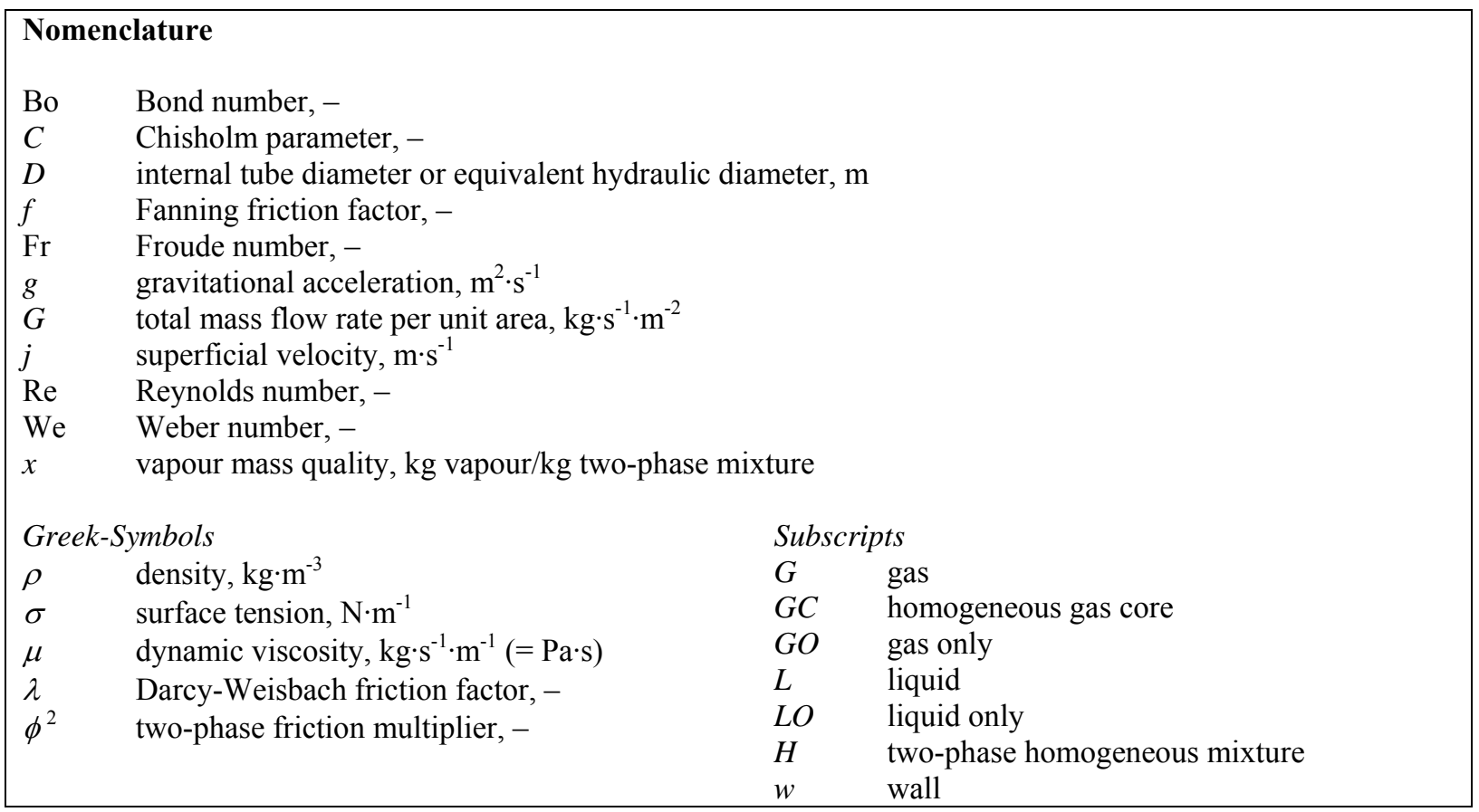

\section{Introduction}

In many thermal systems (like power steam or geothermal plants), an important parameter in the design is the pressure drop for the two-phase flow [1]. Another important area of applications concerns the refrigeration and the air-conditioning systems.

The present study uses the two-phase frictional pressure-drop correlations that are frequently used in the corresponding scientific literature [2]. In this respect, the: 1) homogeneous, 2) Lockhart-Martinelli, 3) Friedel, 4) Chen et al., 5) Cavallini, 6) Müller-Steinhagen \& Heck and 7) 
Jung \& Radermacher models are used, in order to compare them, to see which correlation is applicable under specific operation conditions.

\section{The friction factor}

All the models and correlations used for predicting the pressure drop in tubes use the friction factor formulation. The most common friction factor is the Fanning friction factor, which is defined as the fraction:

$$
f=\frac{\tau_{w}}{\rho u^{2} / 2} \quad, \text { where } \tau_{w} \text { is unit stress at the wall, } \mathrm{N} \cdot \mathrm{m}^{-2}
$$

It must be mentioned that in some research papers, especially in the heat-transfer literature, the Darcy-Weisbach friction factor is used instead of the Fanning friction factor. In this respect, the fact that the Darcy-Weisbach friction factor is related to the Fanning friction factor must be taken into account, as:

$$
\lambda=4 \frac{\tau_{w}}{\rho u^{2} / 2}=4 f
$$

The equations must be further modified accordingly.

Usually, for normal tubes, the Fanning friction factor can be predicted by using different equations for each regime, as the Hagen-Poiseuille correlation for laminar flow and the Blasius correlation for turbulent flow, with a transition region between the laminar and the turbulent flow:

$$
f= \begin{cases}16 \mathrm{Re}^{-1}, & \text { for } \mathrm{Re}<2300 \\ f_{t r}(\mathrm{Re}), & \text { for } 2300 \leq \mathrm{Re}<3000 \\ 0.0791 \mathrm{Re}^{-0.25}, & \text { for } \mathrm{Re} \geq 3000\end{cases}
$$

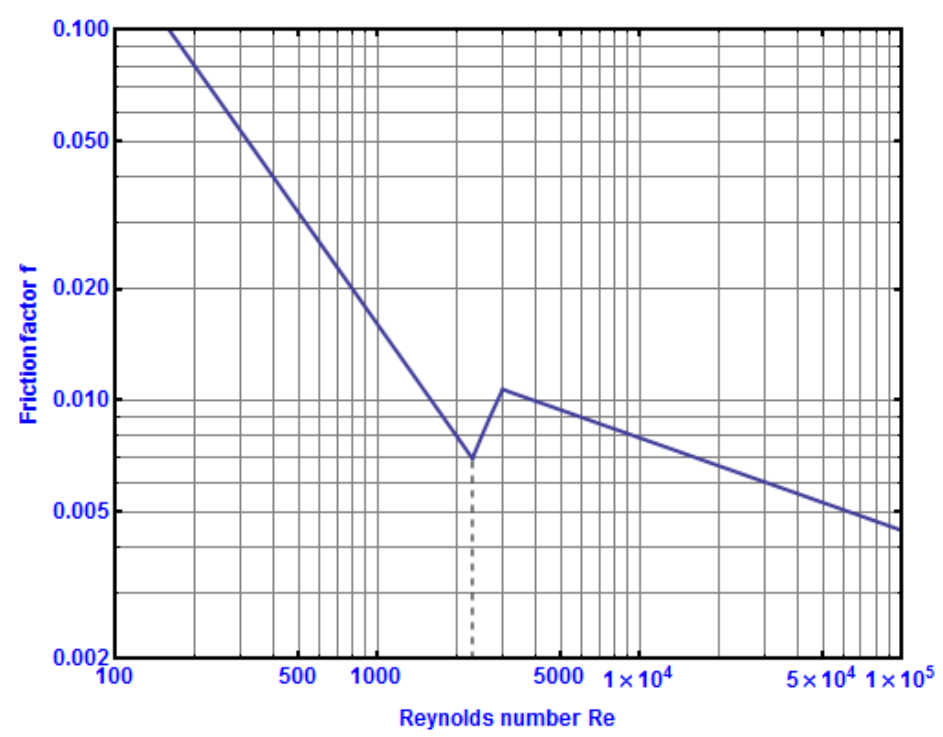

Fig. 1. Fanning friction factor for smooth tubes

A simple linear approximation can be used as (see figure 1):

$$
f_{t r}(\mathrm{Re})=f_{\text {lam }, \mathrm{Re}=2300}+\frac{\left(f_{\text {turb }, \mathrm{Re}=3000}-f_{\text {lam }, \mathrm{Re}=2300}\right)}{3000-2300}(\mathrm{Re}-2300)
$$

However, it must be noted that each model or correlation uses a specific friction factor correlation or specific limits. 


\section{Models and correlations analyzed in this study}

\subsection{The homogeneous model $[1,2]$}

In the homogeneous model, the two-phase flow is treated as an equivalent single-phase flow, having the specific volume of the mixture (two-phase gas-liquid flow) defined as:

$$
v_{H}=x v_{G}+(1-x) v_{L},
$$

and, therefore, the density of the mixture:

$$
\rho_{H}=\frac{1}{v_{H}}=\left(\frac{x}{\rho_{G}}+\frac{1-x}{\rho_{L}}\right)^{-1} \text {. }
$$

The Reynolds number is determined using a homogeneous mixture dynamic viscosity:

$$
\operatorname{Re}=\frac{G d}{\mu_{H}}
$$

the dynamic viscosity of the mixture is, after McAdams:

$$
\mu_{H}=\left(\frac{x}{\mu_{G}}+\frac{1-x}{\mu_{L}}\right)^{-1}
$$

The friction factor is considered as:

$$
f= \begin{cases}16 \mathrm{Re}^{-1}, & \text { for } \mathrm{Re}<2000 \\ 0.079 \mathrm{Re}^{-0.25}, & \text { for } 2000 \leq \mathrm{Re}<20000 \\ 0.046 \mathrm{Re}^{-0.2}, & \text { for } \mathrm{Re} \geq 20000\end{cases}
$$

\subsection{The Lockhart-Martinelli separated flow model $[3,4]$}

Lockhart and Martinelli (1949) [3] proposed the concept of different two-phase friction multipliers (for gas and for liquid), identified as $\phi_{G}^{2}$ and $\phi_{L}^{2}$, respectively.

The pressure drop is then given by:

$$
\begin{aligned}
& \left(\frac{\mathrm{d} p}{\mathrm{~d} z}\right)=\phi_{L}^{2}\left(\frac{\mathrm{d} p}{\mathrm{~d} z}\right)_{L}=\phi_{G}^{2}\left(\frac{\mathrm{d} p}{\mathrm{~d} z}\right)_{G} \\
& \left(\frac{\mathrm{d} p}{\mathrm{~d} z}\right)_{L}=\frac{2 f_{L} G^{2}(1-x)^{2}}{\rho_{L} D} \\
& \left(\frac{\mathrm{d} p}{\mathrm{~d} z}\right)_{G}=\frac{2 f_{G} G^{2} x^{2}}{\rho_{G} D}
\end{aligned}
$$

The two-phase friction multipliers were initially given in a graphical form, and then expressed by Chislom [4] as the following dependence:

$$
\begin{aligned}
& \phi_{L}^{2}=1+\frac{C}{X}+\frac{1}{X^{2}}, \\
& \phi_{G}^{2}=1+C X+X^{2}
\end{aligned}
$$

where the Lockhart-Martinelli parameter $X$ is defined as:

$$
X^{2}=\frac{(\mathrm{d} p / \mathrm{d} z)_{L}}{(\mathrm{~d} p / \mathrm{d} z)_{G}}
$$


The Chisholm parameter depends on the specific liquid/gas viscous/turbulent regime:

$$
C= \begin{cases}5, & \text { for } \operatorname{Re}_{L}<1500 \text { and } \operatorname{Re}_{G}<1500(V-V \text { case }) \\ 10, & \text { for } \operatorname{Re}_{L}>1500 \text { and } \operatorname{Re}_{G}<1500(T-V \text { case }) \\ 12, & \text { for } \operatorname{Re}_{L}<1500 \text { and } \operatorname{Re}_{G}>1500(V-T \text { case }) \\ 20, & \text { for } \operatorname{Re}_{L}>1500 \text { and } \operatorname{Re}_{G}>1500(T-T \text { case })\end{cases}
$$

The liquid and gas Reynolds numbers are determined by using the corresponding mass flow rate per unit area:

$$
\operatorname{Re}_{L}=\frac{[G \cdot(1-x)] \cdot D}{\mu_{L}}, \operatorname{Re}_{G}=\frac{(G \cdot x) \cdot D}{\mu_{G}}
$$

\subsection{The Friedel model [5]}

Friedel proposed a liquid-only multiplier for the frictional pressure drop:

$$
\left(\frac{\mathrm{d} p}{\mathrm{~d} z}\right)=\left(\frac{\mathrm{d} p}{\mathrm{~d} z}\right)_{L O} \cdot \phi_{L O}^{2}
$$

The multiplier is expressed as a function of gas/liquid properties, of vapour mass quality and of gravity and surface tension effects, by using the Froude and Weber numbers:

$$
\begin{aligned}
\phi_{L O}^{2}= & (1-x)^{2}+x^{2}\left(\frac{\rho_{L}}{\rho_{G}}\right)\left(\frac{f_{G O}}{f_{L O}}\right)+ \\
& +3.24 x^{0.78}(1-x)^{0.224}\left(\frac{\rho_{L}}{\rho_{G}}\right)^{0.91}\left(\frac{\mu_{G}}{\mu_{L}}\right)^{0.19}\left(1-\frac{\mu_{G}}{\mu_{L}}\right)^{0.7} \mathrm{Fr}_{t p}^{-0.045} \mathrm{We}_{t p}^{-0.035}
\end{aligned}
$$

The Froude and the Weber numbers are expressed using the homogeneous mixture density:

$$
\mathrm{Fr}_{t p}=\frac{G^{2}}{g D \rho_{H}^{2}}, \mathrm{We}_{t p}=\frac{G^{2} D}{\sigma \rho_{H}}
$$

\subsection{The Chen et al. model (2001) [6]}

This model introduces the dependence on the Bond and Weber number, as a correction of the homogeneous model:

$$
\left(\frac{\mathrm{d} p}{\mathrm{~d} z}\right)=\left(\frac{\mathrm{d} p}{\mathrm{~d} z}\right)_{\text {hom }} \Omega_{\text {hom }}
$$

where the correction factor is:

$$
\Omega_{\text {hom }}= \begin{cases}1+[0.2-0.9 \exp (-\mathrm{Bo})], & \text { for } \mathrm{Bo}<2.5, \\ 1+\mathrm{We} \mathrm{e}^{0.2} /[\exp (\mathrm{Bo})]^{0.3}-0.9 \exp (-\mathrm{Bo}), & \text { for } \mathrm{Bo} \geq 2.5 .\end{cases}
$$

The Bond number is expressed as:

$$
\mathrm{Bo}=g\left(\rho_{L}-\rho_{G}\right) \frac{(D / 2)^{2}}{\sigma}
$$

The Weber number is considered with the homogeneous mixture density:

$$
\mathrm{We}=\frac{G^{2} D}{\sigma \rho_{H}}
$$




\subsection{The Cavallini model [7]}

This model uses the form of the equation (18), however the two phase multiplier correlation is given as a function of vapour and liquid properties, of vapour quality, of reduced pressure $p_{R}$ and of the entrained liquid fraction $E$ :

$$
\phi_{L O}^{2}=Z+3.595 \cdot F \cdot H \cdot(1-E)^{W}
$$

where:

$$
\begin{aligned}
& W=1.398 \cdot p_{R}, p_{R}=\frac{p}{p_{K}} \\
& Z=(1-x)^{2}+x^{2}\left(\frac{\rho_{L}}{\rho_{G}}\right) \cdot\left(\frac{\mu_{G}}{\mu_{L}}\right)^{0.2}, F=x^{0.9525} \cdot(1-x)^{0.414} \\
& H=\left(\frac{\rho_{L}}{\rho_{G}}\right)^{1.132}\left(\frac{\mu_{G}}{\mu_{L}}\right)^{0.44}\left(1-\frac{\mu_{G}}{\mu_{L}}\right)^{3.542}
\end{aligned}
$$

The friction factor (for surfaces with negligible surface roughness) is calculated as:

$$
f_{L O}=0.046 \mathrm{Re}_{L O}^{-0.2}, \text { for any number } \operatorname{Re}_{L O}=\frac{G \cdot D}{\mu_{L}} .
$$

The liquid entrainment ratio $E$ is calculated following Paleev and Filippovich (1966) :

$$
E=0.015+0.44 \cdot \log _{10}\left[\left(\frac{\rho_{G C}}{\rho_{L}}\right)\left(\frac{\mu_{L} j_{G}}{\sigma}\right)^{2} 10^{4}\right]
$$

with the limitations:

$$
\begin{aligned}
& \text { if } E \leq 0 \text { then } E=0 \\
& \text { if } E>0.95 \text { then } E=0.95
\end{aligned}
$$

The superficial gas velocity $j_{G}$ is determined as:

$$
j_{G}=\frac{G \cdot x}{\rho_{G}}
$$

The homogeneous gas core density is defined also as a function of the liquid entrainment ratio $E$ :

$$
\rho_{G C}=[x+(1-x) \cdot E] \cdot\left(\frac{x}{\rho_{G}}+\frac{(1-x) \cdot E}{\rho_{L}}\right)^{-1}
$$

which means that equations (31) and (34) must be solved together, as a nonlinear equation, using an iterative approach.

The correlation applies only if the dimensionless gas velocity $J_{G} \geq 2.5$, where the dimensionless gas velocity is determined as:

$$
J_{G}=\frac{G \cdot x}{\sqrt{g \cdot D \cdot \rho_{G}\left(\rho_{L}-\rho_{G}\right)}}
$$

If $J_{G}<2.5$, the Friedel model is used instead.

\subsection{The Müller-Steinhagen \& Heck model [8]}

The Müller-Steinhagen \& Heck approach consider a combination of each phase only flow, further identified by the subscript $k=\{G O, L O\}$. 
The corresponding Reynolds number is determined with the total mass flow rate per unit area:

$$
\operatorname{Re}_{k}=\frac{G \cdot D}{\mu_{k}}
$$

The friction factor is calculated as:

$$
f_{k}= \begin{cases}16 \mathrm{Re}_{k}^{-1}, & \text { for } \mathrm{Re}_{k} \leq 1187 \\ 0.0791 \mathrm{Re}_{k}^{-0.25}, & \text { for } \mathrm{Re}_{k}>1187\end{cases}
$$

The pressure drop for each phase results:

$$
\left(\frac{\mathrm{d} p}{\mathrm{~d} z}\right)_{k}=\frac{2 f_{k} G^{2}}{\rho_{k} D}
$$

Finally, the pressure drop for the two-phase flow is evaluated as:

$$
\left(\frac{\mathrm{d} p}{\mathrm{~d} z}\right)=\left\{\left(\frac{\mathrm{d} p}{\mathrm{~d} z}\right)_{L O}+2\left[\left(\frac{\mathrm{d} p}{\mathrm{~d} z}\right)_{G O}-\left(\frac{\mathrm{d} p}{\mathrm{~d} z}\right)_{L O}\right] \cdot x\right\}(1-x)^{3}+\left(\frac{\mathrm{d} p}{\mathrm{~d} z}\right)_{G O} \cdot x^{3}
$$

\subsection{The Jung \& Radermacher model [9]}

This approach considers the pressure drop associated to the liquid phase only flow, corrected by a corresponding multiplier, as expressed by equation (18).

The liquid only flow pressure-drop multiplier is given as a function of the vapor mass quality and of the Lockart-Martinelli turbulent-turbulent parameter:

$$
\phi_{L O}^{2}=12.82 \cdot X_{t t}^{-1.47} \cdot(1-x)^{1.8}
$$

The expression for the Lockart-Martinelli turbulent-turbulent parameter is:

$$
X_{t t}=\left(\frac{\mu_{L}}{\mu_{G}}\right)^{0.1}\left(\frac{1-x}{x}\right)^{0.9}\left(\frac{\rho_{G}}{\rho_{L}}\right)^{0.5}
$$

\section{Comparison with experimental data}

\subsection{Comparison with experimental data of Dalkilic (2010) [10]}

First experimental data set used for comparison concerns the annular flow condensation of R600a in a horizontal tube at low mass flux [10].

Table 1

The experimental versus numerical frictional pressure drop, experimental data of Dalkilic (2010)

\begin{tabular}{|c|c|c|c|c||c|c|c|c|c|}
\hline Parameter & $t_{\text {sat }}$ & $G$ & $X_{\text {avg }}$ & $(\mathrm{d} p / \mathrm{dz})_{\exp }$ & $\mathrm{L}-\mathrm{M}$ & Friedel & $\mathrm{Cav}$ & $\mathrm{MSH}$ & $\mathrm{JR}$ \\
\hline Unit & ${ }^{\circ} \mathrm{C}$ & $\frac{\mathrm{kg}}{\mathrm{s} \cdot \mathrm{m}^{2}}$ & - & $\mathrm{Pa} / \mathrm{m}$ & $\mathrm{Pa} / \mathrm{m}$ & $\mathrm{Pa} / \mathrm{m}$ & $\mathrm{Pa} / \mathrm{m}$ & $\mathrm{Pa} / \mathrm{m}$ & $\mathrm{Pa} / \mathrm{m}$ \\
\hline Exp.\# 1 & 30 & 85 & 0.85 & 850 & 500 & 718 & 753 & 646 & 854 \\
\hline Exp.\#2 & 30 & 85 & 0.70 & 700 & 654 & 625 & 700 & 546 & 920 \\
\hline Exp.\#3 & 30 & 75 & 0.90 & 775 & 427 & 598 & 597 & 535 & 610 \\
\hline Exp.\#4 & 30 & 75 & 0.60 & 625 & 519 & 450 & 508 & 378 & 691 \\
\hline Exp.\# 5 & 43 & 115 & 0.85 & 875 & 785 & 883 & 891 & 785 & 1129 \\
\hline Exp.\# 6 & 43 & 115 & 0.55 & 475 & 899 & 634 & 703 & 527 & 1072 \\
\hline Exp.\#7 & 43 & 95 & 0.85 & 800 & 462 & 640 & 639 & 562 & 808 \\
\hline Exp.\# 8 & 43 & 95 & 0.45 & 450 & 598 & 397 & 427 & 318 & 648 \\
\hline
\end{tabular}

L-M: Lockart-Martinelli, Cav: Cavallini, MSH: Müller-Steinhagen \& Heck, JR: Jung \& Radermacher 
The specific conditions, the experimental data, and the numerical results are presented in Table 1.

The calculation pressure drop versus the experimental pressure drop is represented in figures 3 and 4 , where the $\pm 30 \%$ error lines are shown.

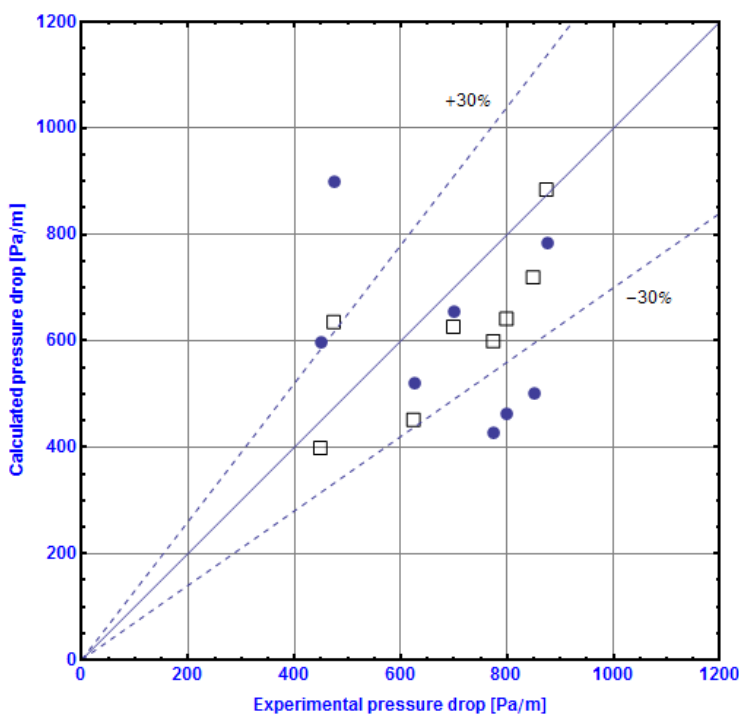

Fig. 3. Calculation versus experimental pressure drop, R600A

Lockart-Martinelli (“•”) and Friedel (“口”)

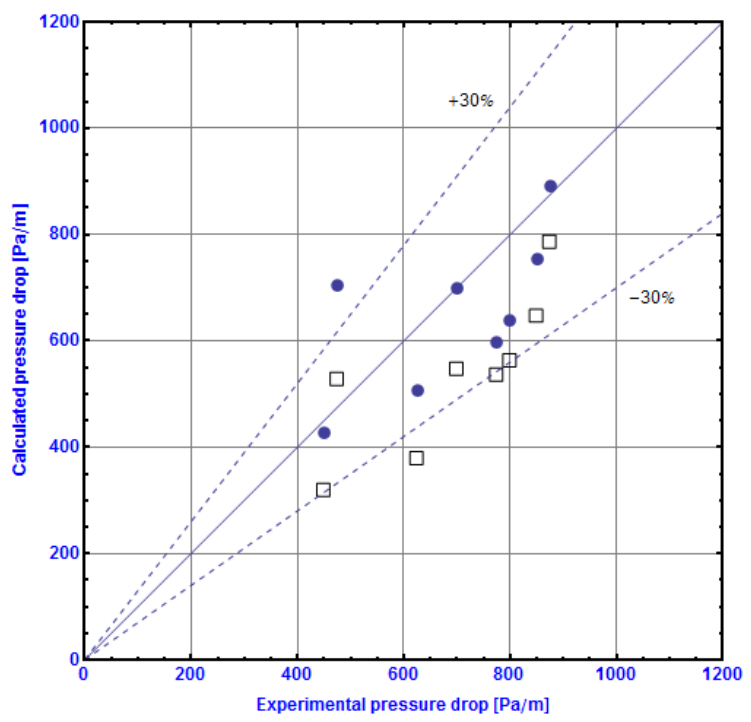

Fig. 4. Calculation versus experimental pressure drop, R600A

Cavallini ("•") and MSH (“口”)

Figures 5 and 6 present the variation of the pressure drop with the vapour quality, and with the total mass flow rate per unit area, respectively, giving the possibility to analyze the behavior of the models. A general observation can be made, that is, models usually follow the trend of the experimental data, however in a quite different slope. Another observation concerns the fact that in this application the models under-estimate the experimental pressure-drop. Finally, there are strong connections between parameters, so a multi-criterial approach should be used; however, for such analysis, supplementary parametric variations of the experimental data are needed.

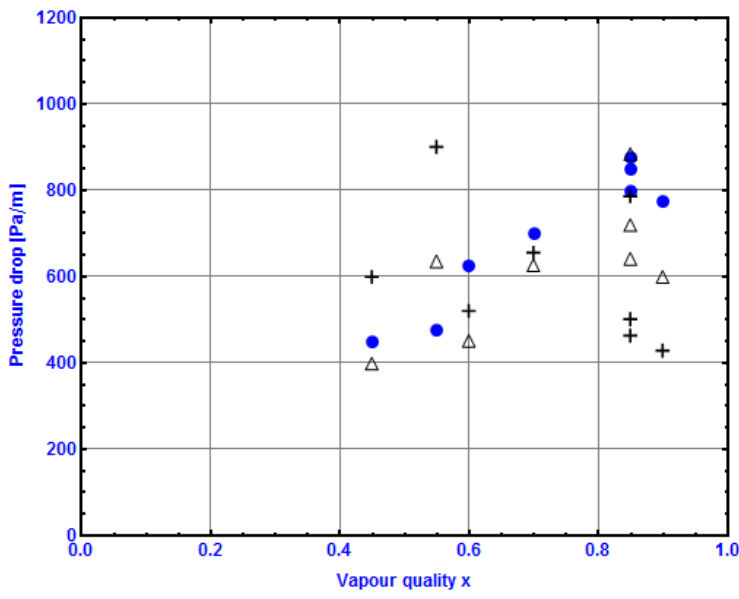

Fig. 5. Variation of the pressure drop with the vapour quality, R600A

Experimental ("• "), Lockart-Martinelli (“+”) and Friedel (" $\Delta ")$

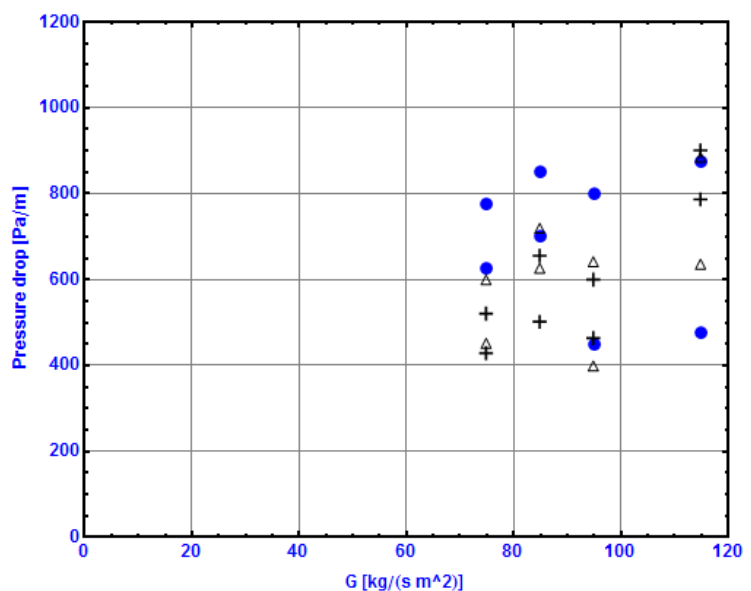

Fig. 6. Variation of the pressure drop with the total mass flow rate per unit area, R600A Experimental (" "), Lockart-Martinelli ("+ ") and Friedel (" $\Delta ")$

\subsection{Comparison with experimental data of da Silva Lima (2009) [11]}

Another experimental data set used for comparison concerns the condensation of R717 $($ Ammonia $=\mathrm{NH} 3)$, flowing in a horizontal smooth tube. 
The comparisons of the experimental and the numerical results are shown in figures 7-10, for different condensation temperatures and total mass fluxes per unit area.

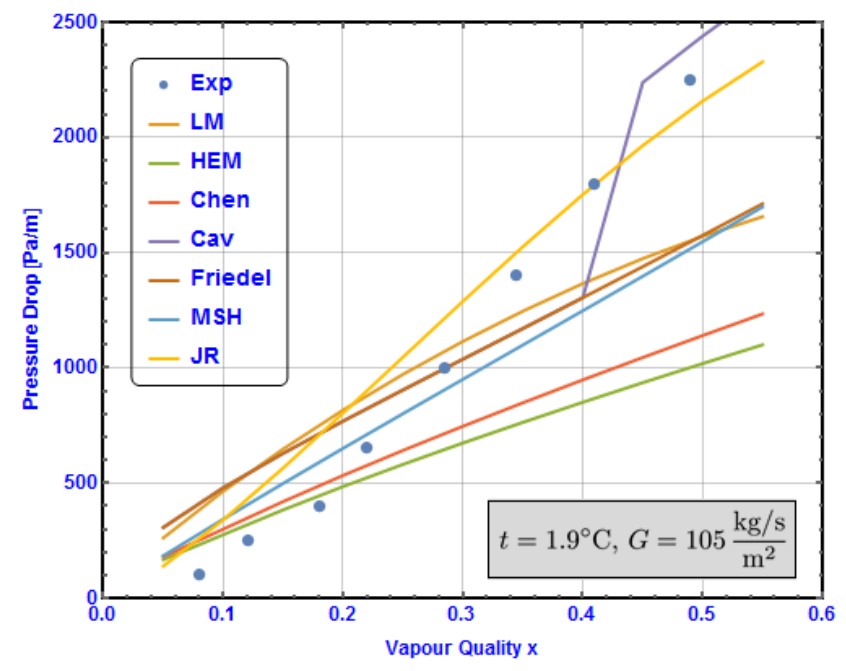

Fig. 7. Calculation versus experimental pressure drop, R717, case 1

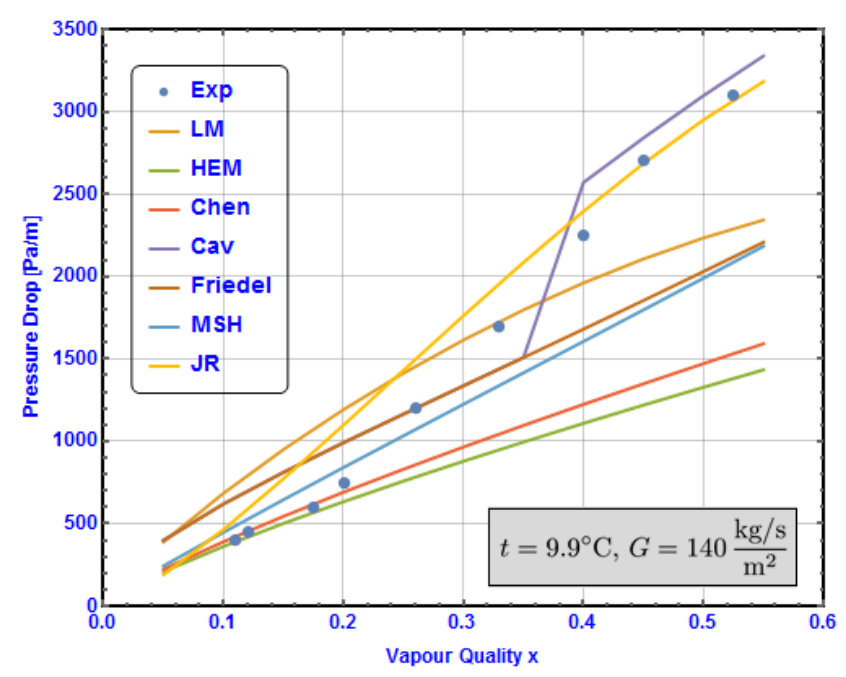

Fig. 9. Calculation versus experimental pressure drop, R717, case 3

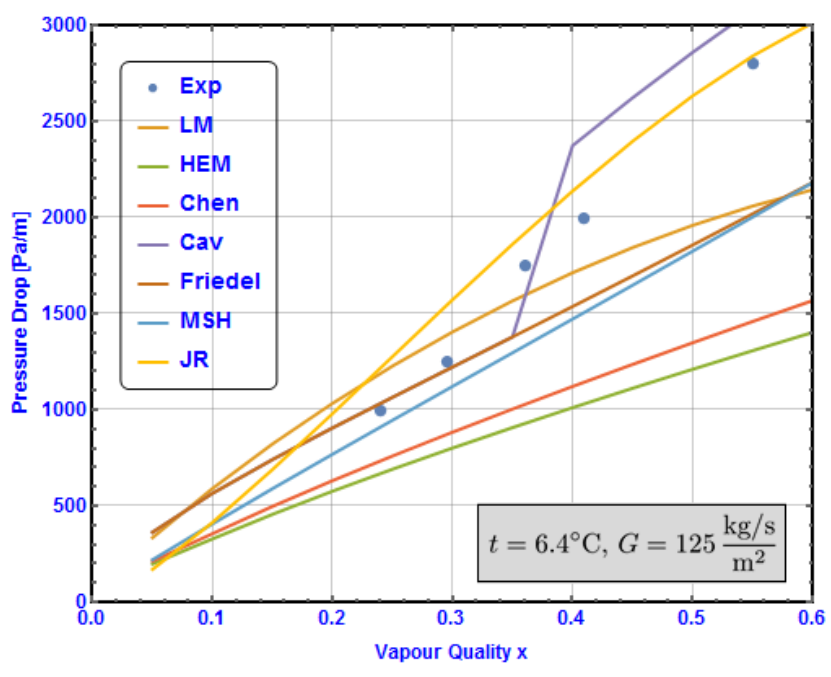

Fig. 8. Calculation versus experimental pressure drop, R717, case 2

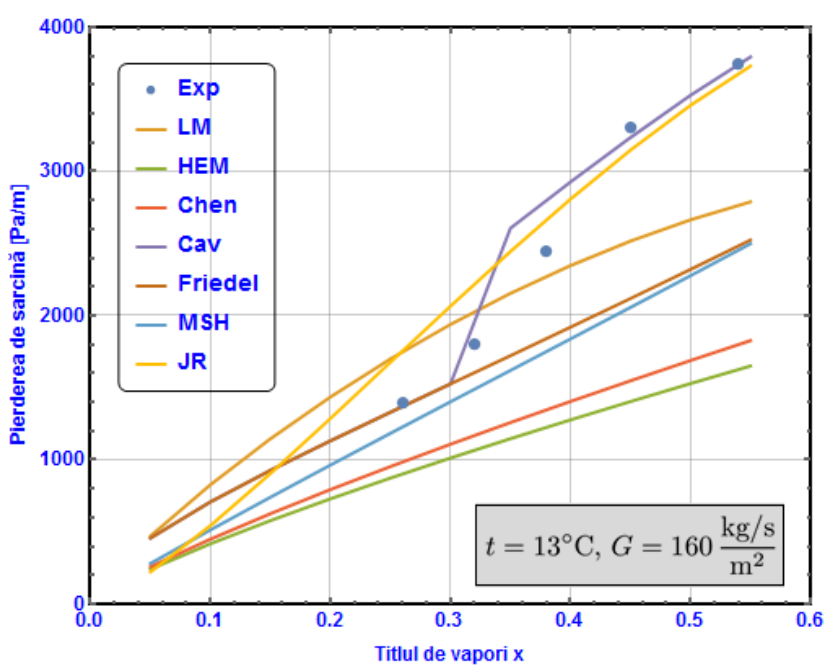

Fig. 10. Calculation versus experimental pressure drop, R717, case 4

For low values of the vapour mass quality $(0.1 \ldots 0.2 \mathrm{~kg}$ vapour $/ \mathrm{kg}$ two-phase mixture), one can observe that the homogeneous and Chen models are the best suited models. Instead, for the range $0.25 \ldots 0.35$, the best suited models are Friedel, Müller-Steinhagen \& Heck and LockhartMartinelli. For values of the vapour quality greater than 0.4 , the Jung \& Radermacher and Cavallini correlations provide the best behavior. On an overall basis in the $0.1 \ldots 0.6$ range, the Cavallini correlation (which completes the Friedel correlation) gives the best approximation of the da Silva experimental data. One can also observe that Lockhart-Martinelli also gives a good overall approximation.

\section{Conclusions}

The present study concerns the comparison of the numerical results regarding the two-phase pressure-drop in pipes with the experimental results found in the scientific literature, for the condensation of R600A and R717 in horizontal tubes, in different operation conditions. The study reveals the behavior of the considered models and the importance of the value of the vapour mass quality. The overall behaviour of the models has been also analyzed. 


\section{References}

[1] Popescu Fl., Andrei V. \& Damian R.M. (2005). Dinamica fluidelor polifazice, Galaţi: Editura Fundaţiei Universitare "Dunărea de Jos".

[2] Kim S.-M., Mudawar I. (2014). Review of databases and predictive methods for pressure drop in adiabatic, condensing and boiling mini/micro-channel flows, International Journal of Heat and Mass Transfer, 77, $74-97$. DOI: 10.1016/j.ijheatmasstransfer.2014.04.035.

[3] Lockhart R.W., Martinelli R.G. (1949). Proposed correlation of data for isothermal two-phase, two-component flow in pipes. Chem. Eng. Prog. 45(1), pp. 39-48.

[4] Chisholm D. (1967). A theoretical basis for the Lockhard-Martinelli correlation for two-phase flow, International Journal of Heat and Mass Transfer, 10, 1767-1778. DOI: 10.1016/0017-9310(67)90047-6.

[5] Friedel L. (1979). Improved friction pressure drop correlations for horizontal and vertical two-phase pipe flow, In European Two-Phase Group Meeting, Ispra, Italy, Paper E2.

[6] Chen I.Y., Yang K.-S., Chang Y.J., Wang C.-C. (2001). Two-phase pressure drop of air-water and R-410A in small horizontal tubes, International Journal of Multiphase Flow, Volume 27, 1293-1299. DOI: 10.1016/S0301-9322(01)00004-0.

[7] Cavallini A., Rossetto L., Matkovic M., Del Col D. (2005). A model for frictional pressure drop during vapour-liquid flow in minichannels. IIR International Conference Thermophysical Properties and Transfer Processes of Refrigerants, 31 August-2 September, Vicenza, Italy , pp. 71-78.

[8] Müller-Steinhagen H., Heck K. (1986). A Simple Friction Pressure Drop Correlation for Two-Phase Flow in Pipes, Chem. Eng. Process., 20, 297-308. DOI: 10.1016/0255-2701(86)80008-3.

[9] Jung D.S., Radermacher R. (1989). Prediction of pressure drop during horizontal annular flow boiling of pure and mixed refrigerants, Int. J. Heat Mass Transfer, 32, 2435-2446. DOI: 10.1016/0017-9310(89)90203-2.

[10] Dalkilic A.S., Agra O., Teke I., Wongwises S. (2010). Comparison of frictional pressure drop models during annular flow condensation of R600a in a horizontal tube at low mass flux and of R134a in a vertical tube at high mass flux, International Journal of Heat and Mass Transfer, 53, 2052-2064. DOI: 10.1016/j.ijheatmasstransfer.2008.12.001.

[11] da Silva Lima R.J., Quiben J.M., Kuhn C., Boyman T., Thome J.R. (2009). Ammonia two-phase flow in a horizontal smooth tube: Flow pattern observations, diabatic and adiabatic frictional pressure drops and assessment of prediction methods, International Journal of Heat and Mass Transfer, 52, 2273-2288. DOI: 10.1016/j.ijheatmasstransfer.2008.12.001. 